\title{
Sex and strife: post-conflict sexual contacts in bonobos
}

\author{
Zanna Clay* and Frans B.M. de Waal \\ Living Links, Yerkes National Primate Research Center and Psychology Department, \\ Emory University, Atlanta, GA, USA \\ *Corresponding author's e-mail address: zannaclay@emory.edu
}

Accepted 15 October 2013; published online 12 February 2014

\begin{abstract}
Sexual contacts are thought to play an important role in regulating social tension in bonobos (Pan paniscus), and are especially common following aggressive conflicts, either between former opponents or involving bystanders. Nevertheless, research on the factors determining post-conflict sexual contacts, their effectiveness in reducing social tension and the nature of post-conflict sexual behaviour is scarce. Here, we collected data on post-conflict affiliative contacts in bonobos occurring between former opponents (reconciliation) and offered by bystanders towards victims (consolation) to investigate the role of sexual contacts in the regulation of aggressive conflicts compared to non-sexual affiliation behaviours. We tested whether post-conflict sexual contacts: (1) alleviate stress, (2) confer reproductive benefits, (3) mediate food-related conflict and (4) repair valuable social bonds. Thirty-six semi-free bonobos of all ages were observed at the Lola ya Bonobo Sanctuary, DR Congo, using standardized Post-Conflict/Matched Control methods. Consolation and reconciliation were both marked by significant increases in the occurrence of sexual behaviours. Reconciliation was almost exclusively characterized by sexual contacts, although consolation was also characterized by increases in non-sexual behaviours, such as embrace. Adults were more likely to engage in post-conflict sexual contacts than younger bonobos. Consistent with the stress-alleviation hypothesis, victims receiving sexual consolatory contact showed significantly lower rates of self-scratching, a marker of stress in primates, compared to receiving non-sexual contact. Post-conflict sexual contacts were not targeted towards valuable social partners and they did not confer obvious reproductive benefits; nor were they used to mediate food-related conflicts. Overall, results highlight the role of sex in regulating tension and social conflicts in bonobos.
\end{abstract}

\section{Keywords}

post-conflict behaviour, consolation, reconciliation, socio-sexual behaviour, tension regulation, primate. 


\section{Introduction}

Bonobos (Pan paniscus) are well known for possessing a particularly rich and heightened socio-sexuality (Thompson-Handler et al., 1984; de Waal, 1987, 1995; Furuichi, 1989; Kano, 1989; White, 1996; Hashimoto, 1997; Hohmann \& Fruth, 2000; Hohmann et al., 2009; Clay et al., 2011). Sex is freely incorporated into their daily life, with individuals habitually engaging in sexual interactions in all age and sex combinations. Bonobo females remain sexually active across their sexual cycles and, unlike most other primates, engage in face-to-face sexual interactions (e.g., Thompson-Handler et al., 1984; Kano, 1992; Paoli et al., 2006). Genito-genital contacts are a hallmark of their socio-sexual behaviour, during which two individuals, most commonly females, embrace ventro-ventrally, swing their hips laterally while keeping their vulva in contact (Kuroda, 1980; Hohmann \& Fruth, 2000, Figure 1).

Socio-sexual contacts are thought to help regulate stress in bonobos, acting as a kind of 'social grease', to alleviate tension and to facilitate peaceful co-existence between group members, who generally lack close genetic ties (de Waal, 1987; Hohmann \& Fruth, 2000; Fruth \& Hohmann, 2006). Consistent with Hanby's (1977) prediction about the stress relieving function of primate socio-sexual contacts, most non-conceptive sexual behaviours in bonobos occur within socially tense periods, such as feeding, anticipation of feeding, inter-group interactions and following aggressive conflicts (Mori, 1983; de Waal, 1987; Manson et al., 1997; Hohmann \& Fruth, 2000; Paoli et al., 2006; Hohmann et al., 2009).

Like any socially foraging animal, feeding is a source of contention in bonobos and sex appears to regulate feeding competition and facilitate food sharing (i.e., Parish, 1994; Hohmann et al., 2009). For instance, individuals offering sexual contacts to food possessors are more likely to gain access to the feeding source (Kuroda, 1984; Thompson-Handler et al., 1984; de Waal, 1987; Kano, 1992). With the relation between food and tension, most studies focus have focused on socio-sexual behaviour in the feeding context (e.g., Parish, 1994; Hohmann et al., 2009), consequently leaving investigation into its role in other contexts somewhat neglected. In one study however, Hohmann \& Fruth (2000) showed that genital contacts in wild females increased between opponents following conflicts, a finding that warrants further investigation. 

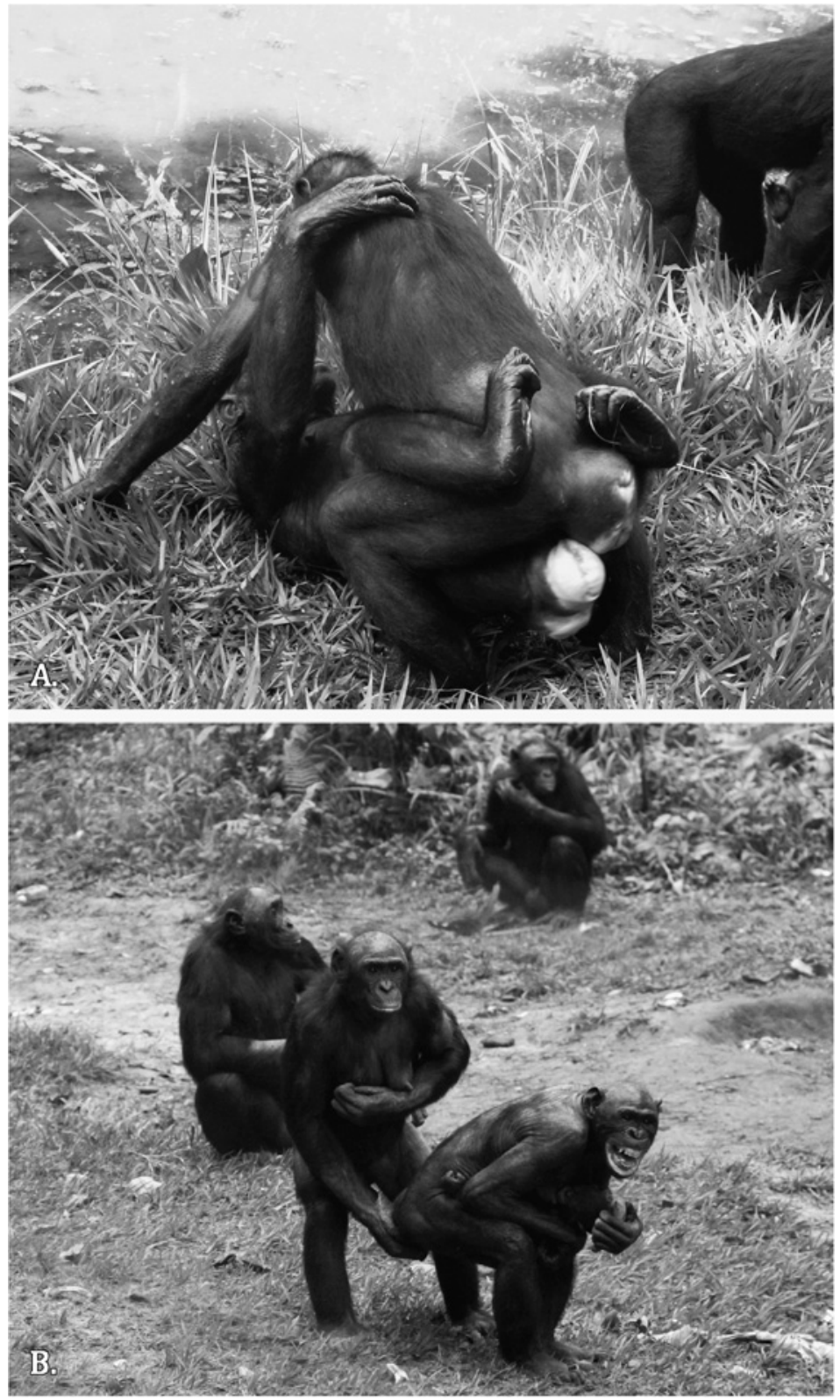

Figure 1. Socio-sexual behaviour in bonobos. (A) Female-female genito-genital contact; (B) a female bystander offering a genital touch towards a distressed victim following a conflict. Photographer: Zanna Clay at Lola ya Bonobo Sanctuary. 
In response to the apparent scarcity of systematic data on bonobo sociosexual behaviour in other contexts, this study examined the use and function of socio-sexual behaviours in another pertinent context, post-conflict interactions. As post-conflict interactions have, themselves, received considerable attention in the animal behaviour literature, it is useful to first lay out the basic framework and relevant concepts for studying post-conflict interactions and why this context is interesting for exploring the use and function of sex in bonobos.

Following aggressive conflicts, former opponents often engage in various forms of affiliative contacts, a reparative process known as reconciliation (de Waal \& van Roosmalen, 1979; de Waal \& Aureli, 1996; Arnold et al., 2001). In bonobos, these contacts are more often sexual in nature (de Waal, 1987, 1992; Manson et al., 1997; Hohmann \& Fruth, 2000; Palagi et al., 2004), although various post-conflict behaviours are used in primates and other animals (e.g., de Waal, 1989; Fraser et al., 2008). For instance, chimpanzees reconcile primarily using embrace, kissing, 'finger in mouth' and touching (Fraser et al., 2008). In addition to reconciliation, uninvolved bystanders sometimes initiate affiliative contacts with one of the contestants, typically the former victim (de Waal \& Roosmalen, 1979; de Waal \& Aureli, 1996). Bystanders can accrue various direct benefits by doing so, such as protection from redirected aggression (e.g., Fraser et al., 2009). In a select number of species, however, the offering of friendly contacts appears to be more driven by a motivation to reduce the distress of a close social partner or kin-member, based on an apparent absence of purely self-serving benefits (chimpanzees, P. troglodytes: e.g., de Waal \& van Roosmalen, 1979; Koski \& Sterck, 2007; Fraser \& Aureli, 2008; Romero et al., 2011; bonobos: Palagi et al., 2004; Clay \& de Waal, 2013a; gorillas, Gorilla gorilla: Cordoni et al., 2006; crows, C. corax: Fraser \& Bugnyar, 2010: dogs, Canis familiaris: Cools et al., 2008; wolves, C. lupus: Palagi \& Cordoni, 2009: African elephants, Loxodonta africana: Byrne et al., 2008). This type of affiliative act, known as 'consolation', has been shown to be effective in reducing the recipient distress (e.g., Fraser et al., 2008; Clay \& de Waal, 2013a). With a shift towards the other, consolation is considered an important bridge between expressions of empathy in animals and humans, as it suggests that the consoler can recognize as well as respond appropriately to alleviate anothers' distress (e.g., Preston \& de Waal, 2002; Romero et al., 2010). 
While sex is thought to play a key role during bonobo post-conflict interactions (i.e., de Waal, 1987; Hohmann \& Fruth, 2000), there has been little systematic investigation. To address this, we used data collected on post-conflict interactions of two large social groups of semi-free bonobos to examine different hypotheses relating to the function of post-conflict sexual contacts. We explored the tension regulation hypothesis, as despite much discussion on the subject, there has been little empirical investigation into its efficiency in reducing tension as opposed to other non-sexual affiliative contacts. We compared this with three alternative hypotheses; post-conflict sexual contacts confer reproductive benefits; post-conflict sexual contacts resolve fights relating to food-competition and finally; post-conflict sexual contacts repairs valuable social bonds.

\subsection{Post-conflict sexual contact alleviates stress}

Despite much discussion on the topic (e.g., Kuroda, 1984; de Waal, 1987; Kano, 1989; Hohmann \& Fruth, 2000; Fruth \& Hohmann, 2006; Paoli et al., 2006), the tension regulation hypothesis has only been directly tested in one study (Hohmann et al., 2009), which examined the temporal relationship between salivary cortisol, a biomarker for social stress (e.g., Sapolsky, 2004), and genital contacts during a competitive feeding task. In this study, social stress was induced by providing restricted or unrestricted access to food. The results were equivocal. While the occurrence of genital contacts was temporally associated with increased cortisol and with the anticipation of food, higher rates of genital contacts did not correlate with greater reductions in cortisol. However, this study suffered from methodological limitations such as a small sample size and incomplete hormonal sampling. Moreover, it only focused on genital contacts during competitive feeding, rather than other forms of sexual behaviours and other contexts.

Applying the stress alleviation hypothesis to the post-conflict context, we predicted that rates of self-scratching of victims, a behavioural marker of social stress in primates (Maestripieri et al., 1992; Schino et al., 1996; Fraser et al., 2008), should be lower in victims that had received sexual forms of post-conflict affiliative contact rather than non-sexual ones.

\subsection{Post-conflict sexual contact confers reproductive benefits}

While post-conflict sexual behaviours are typically considered as social acts in bonobos, copulations may also occur following conflicts and other socially 
tense periods (de Waal, 1987), suggesting that individuals could also confer some reproductive benefits by offering or being offered copulations. These benefits may be further enhanced by the fact that bonobo females exhibit an especially prolonged period of oestrous compared to other primates, both in terms of extended swelling cycles and in the duration of the peak swelling phase (Thompson-Handler et al., 1984; Dahl, 1986; Blount, 1990). Under this hypothesis, copulations should therefore be expected to be a regular form of sexual contact; moreover, they should be primarily initiated by sexually mature individuals to sexually mature recipients of the opposite sex.

\subsection{Sexual contact mediates food-related conflicts}

Numerous studies have shown a relationship between socio-sexual behaviours and feeding competition (e.g., de Waal, 1987; Parish, 1994; White, 1996; Hohmann et al., 2009). If sex mediates food-related conflicts, sex should be more likely to occur following food-related conflicts than nonfood related conflicts.

\subsection{Post-conflict sexual contact repairs valuable social bonds}

It has been proposed that sexual contacts consolidate and repair social bonds (de Waal, 1987, 1989; Hohmann \& Fruth, 2000). This hypothesis predicts that sex would be most likely between dyads sharing a strong affiliative relationship. An alternative is that sexual contacts, more than non-sexual contacts, are facilitated by the trust that exists in dyads with strong affiliative relationships. Sexual contact in socially distant dyads may be perceived as too risky and therefore be less common.

\section{Methods}

\subsection{Study site and subjects}

Observations were conducted at the Lola ya Bonobo Sanctuary, Kinshasa, DR Congo. All information about the study site is provided in Clay \& de Waal (2013a, b), which is based on the same data set used here. We conducted observations at the two largest enclosures, Group 1 and Group 2. Group 1 comprised of 25 individuals ( 6 adult females, 3 adult males and 16 immatures) and Group 2 comprised of 17 individuals ( 3 adult females, 4 adult males and 10 immatures; Clay \& de Waal, 2013a). As exact birth dates for orphans were unknown, we used age estimates made by sanctuary 
veterinarians upon each bonobo's arrival, which were adjusted based on measurements of weight and patterns of dental emergence according to known patterns of ape development (Wobber et al., 2010; Rosati \& Hare, 2012). This was validated by the known exact ages of individuals born at the sanctuary.

\subsection{Data collection}

From May-August 2011, observations were conducted by Z.C. and a trained assistant throughout the day $(N=301$ and 152 observation hours recorded at Groups 1 and 2). We conducted all-occurrence observations of agonistic interactions that included at least one of the following behavioural elements: recipient fleeing and/or screaming in reaction to aggression, aggressor threat barks/grunts, directed display charge, threat arm wave, chase, hit, trample, slap, shove, poke, or bite. For each agonistic interaction, we recorded the identities of the initial recipient of the aggression, termed the 'victim', and the aggressor, as well as the identities of all visible bystanders. We also recorded the conflict context (see Clay \& de Waal, 2013a, b) and the conflict intensity, which ranged from (1) threat (hand shake, bipedal swagger, threat bark, lunge); (2) directed display/charge without physical contact; (3) chase pursuit/quick poke/shove; (4) single grab/hit/slap without biting; (5) severe/multiple grab/hit or biting; to (6) injurious physical attack or biting (de Waal, 1988).

For each interaction, we conducted focal sampling of the victim using the standardized Post Conflict-Matched Control method (de Waal \& Yoshihara, 1983). Post-conflict (PC) focals consisted of a 10-min focal observation of the victim immediately following the conflict. Each focal was matched with a 10-min Matched Control (MC) focal of the same victim on the following day ( \pm 2 days) at the same or closest possible time $( \pm 1 \mathrm{~h})$. Further detail is provided in Clay \& de Waal (2013a, b). We recorded all instances of affiliative contacts between the focal and the original opponent or any bystander. We coded the occurrence of nine different classes of contact behaviours: Embrace, Groom, Contact-sit, Touch, Play, Contact-peer, Pat, Hold and Sexual contact behaviours (Embrace, actor places arm around the recipient; Grooming, directed cleaning/inspection of the hair/skin; Contact-sit, sitting in physical contact; Touch, soft touch/stroke to the recipient's body, other than genitals, using a non-genital body part; Play, wrestle/run/chase/tickle with play face/laugh; Contact peer, approach close to peer at recipient, resulting in contact; Pat, tap/pat contact onto recipient's body using flat hand; 
Hold, grasp/hold onto recipient (generally when walking)). Sexual contact included: Genito-genital rubbing (partners embrace ventro-ventrally and swing their hips laterally, keeping their vulvae in contact), mounting (lateral contact of the actors genitals behind the recipient and thrusting onto the recipient's behind), copulation (penile intromission and pelvic thrusting) and genital touching (touching the recipient's genitals using a non-genital body part, such as hand). We recorded the initiator of each interaction, which was the individual starting the interaction.

We collected data on rates of self-scratching per minute during all focals, a behavioural marker of social stress in primates (Maestripieri et al., 1992; Schino et al., 1996; Fraser et al., 2008). Focals were filmed using a Canon Vixia HF200 HD Camcorder. Aside from interactions involving dependent infants, interactions involving all individuals were included in the analyses.

In order to construct affinity matrices, instantaneous scan samples of all visible individuals were carried out throughout the day at 10-min intervals. The identities of all visible party members were recorded, followed by the identities of all individuals engaging in: grooming, contact sitting, sitting within arms reach, play or sexual contact (data on these state behaviours are distinct to the focal data). We collected a total of 794 and 411 scans at Groups 1 and 2, respectively. Interactions between all individuals, except dependent infants, were recorded.

\subsection{Ethical approval}

We received permission from 'Les Amis des Bonobos du Congo' (ABC) and full ethical approval from Les Amis de Bonobos du Congo (ABC) Scientific Committee and its Scientific Coordinator to conduct this study. The study complied with all legal requirements required for conducting research in the DR Congo and was approved by Emory University's IACUC committee.

\subsection{Data analysis}

In previous analyses, using the PC-MC method (de Waal \& Yoshihara, 1983), on the same data set used here, we demonstrated significant occurrence of both consolation and reconciliation (Clay \& de Waal, 2013a), where consolation and reconciliation were defined as increased contact affiliation spontaneously offered by the bystander toward the victim or between opponents during PC periods as compared with MCs. Having demonstrated consolation using this data set, we broadened the definition of consolation in the present 
analyses to be the spontaneous offering of contact affiliation by a bystander towards the victim. Likewise, reconciliation was defined as any affiliative contact occurring between former opponents during the PC period. As we were interested in affiliation offered by bystanders, any affiliations initiated by the victim itself towards a bystander were excluded.

As we were interested in the behaviours offered during consolation, we only examined PC interactions in which a bystander offered contact affiliation to the victim, which resulted in $N=237$ events. However, as previous studies have shown that reconciliation can influence the occurrence of consolation, we removed cases where consolation co-occurred with reconciliation. This resulted in $N=175$ interactions available for analysis ( $N=31$ victims, $N=26$ aggressors). For each interaction, we compared the occurrence of different affiliation behaviours with those offered by bystanders to the same victim during MCs $(N=139 \mathrm{MCs}$ in which bystanders initiated contact affiliation). The lower number of MCs reflects the lower occurrence of contact affiliations occurring during baseline periods (Clay \& de Waal, 2013a).

We examined the behavioural nature of reconciliation. As there were very few cases where reconciliation occurred in the absence of consolation, we included reconciliation that occurred before consolation, resulting in $N=65$ $\mathrm{PC}$ and $N=35 \mathrm{MC}$ events.

\subsubsection{The nature of consolation and reconciliation behaviour in bonobos}

We used Generalized Linear Mixed Models (GLMM; binomial logit) to examine the extent to which PC periods influenced the offering of specific forms of affiliation behaviours by bystanders towards victims (consolation) and between opponents (reconciliation). We conducted GLMMs using the 'Imer' function in the R package 'Ime4'. To examine the role of sexual contacts in PC interactions, we conducted a GLMM on the occurrence of sexual contacts as the binomial dependent variable (yes/no) and context (PC or control) as the fixed factor. For consolation, these were sexual contacts initiated by the bystander to the victim and for reconciliation, the sexual contacts occurring between former opponents. All forms of sexual contacts were included in the 'sex' category (explored individually in subsequent analyses). We controlled for repeated sampling and inter-individual/group variation by including five random effects: the identities of Victim, Aggressor and Bystander; Group (1 or 2); and Interaction number. To compare between sexual and non-sexual contacts, we conducted a GLMM on the occurrence 
of Embrace, Play and Grooming during PC periods as compared to controls; behaviours all known to be especially relevant to social affiliation in bonobo sociality. We conducted GLMMs on each of these behavioural types using the same Fixed and Random Factors as above, with the occurrence of a given behaviour (yes/no) entered as the binomial dependent variable. We applied the Sidak correction in order to control for multiple comparisons $(\alpha=0.013)$. For reconciliation, we were not able to examine the frequency of these non-sexual contact behaviours (Embrace, Play, Grooming) owing to inadequate sample size of occurrence.

\subsubsection{The use and determinants of post-conflict sexual contacts}

In order to examine some of the determinants of PC sexual contacts, we conducted a GLMM on the occurrence of sexual contacts (yes/no) as the binomial dependent variable and the age (adult, adolescent, juvenile) and sex (male, female) of the bystander and the victim as fixed factors. We included the victim, bystander and aggressor identities as random factors, as well as the Interaction number and Group number. We conducted GLMMs for sexual contacts during consolation and during reconciliation. We computed all possible models using different combinations of the predictor variables. The best model was selected using the Akaike's information criterion (AIC), which compares multiple models and identifies the most parsimonious model that best explains the variance of the dependent variable, while penalizing for the number of variables in the model. The best model, as indicated by having the lowest AIC value, is the best model to predict values of the dependent variable in a new data set (Tabachnik \& Fidell, 2001).

\subsubsection{Does post-conflict sexual contact alleviate victim stress? Previ-} ously, using this data set, we demonstrated that consolation of any type reduced victim self-scratching as compared to receiving no consolation (Clay \& de Waal, 2013a). In order to examine whether sexual contact had a more effective stress-alleviating effect compared to non-sexual contact, we used a Wilcoxon Signed Ranks test to compare mean victim self-scratch rates (per min) during PC periods in which a bystander offered sexual contact compared to non-sexual contact (i.e., touch, pat, groom, play). We removed cases in which consolation co-occurred with reconciliation in order to control for any confounding effects. We also examined whether victim self-scratch rates were lower following the occurrence of reconciliatory sexual contacts between compared to non-sexual reconciliation. 
2.4.2.2. Does post-conflict sexual contact confer reproductive benefits? To examine whether PC sexual contact confers reproductive benefits, we compared the proportions of conceptive sexual contacts (copulation) with nonconceptive sexual contacts and calculated the percentage of sexual contacts that could potentially result in conception (the frequencies of copulations occurring between adult and adolescents). Adolescents were included based on the fact that bonobo adolescents have been shown to be capable of conception/insemination (e.g., San Diego Zoo, Twycross Zoo, Lola ya Bonobo).

2.4.2.3. Does sexual contact mediate food-related conflicts? To explore whether bonobos used sexual contacts to mediate food-related conflicts, we used GLMMs to examine whether the occurrence of consolatory and reconciliatory sexual contacts were more likely during food-related conflicts than non-food related conflicts. For both the consolation and reconciliation GLMMs, the occurrence of sexual contact (yes/no) was entered as the dependent variable, and Feeding Context was entered as the fixed factor (feed/nonfeed). The random effects were the same as described above.

2.4.2.4. Does post-conflict sexual contact repair valuable social bonds? Previously, we showed that consolation and reconciliation were positively predicted by affiliation between victims and bystanders or, for reconciliation, between opponents (Clay \& de Waal, 2013a, b). To examine whether affiliation positively predicted the occurrence of sexual contacts, we ran consolation and reconciliation GLMMs, where occurrence of sexual contacts (yes/no) was entered as the dependent variable and Affiliation was entered as the fixed factor. Individual identities, group and file number were entered as random factors.

\section{Results}

\subsection{The nature of consolation and reconciliation behaviour in bonobos}

There was considerable variation in the rates of different PC contact behaviours offered to victims by bystanders as compared to MCs (Figure 2). A $\chi^{2}$-test on the pooled frequencies of each different behavioural types $(N=9)$ revealed significant differences in their relative frequencies during PC periods as compared to MCs $\left(\chi^{2}=101.70, \mathrm{df}=8, p<0.001\right)$. Whereas contact sitting, play, touch and grooming were typical during control periods, PC interactions showed notable increases in sexual behaviour, embrace, holding and contact peering. 

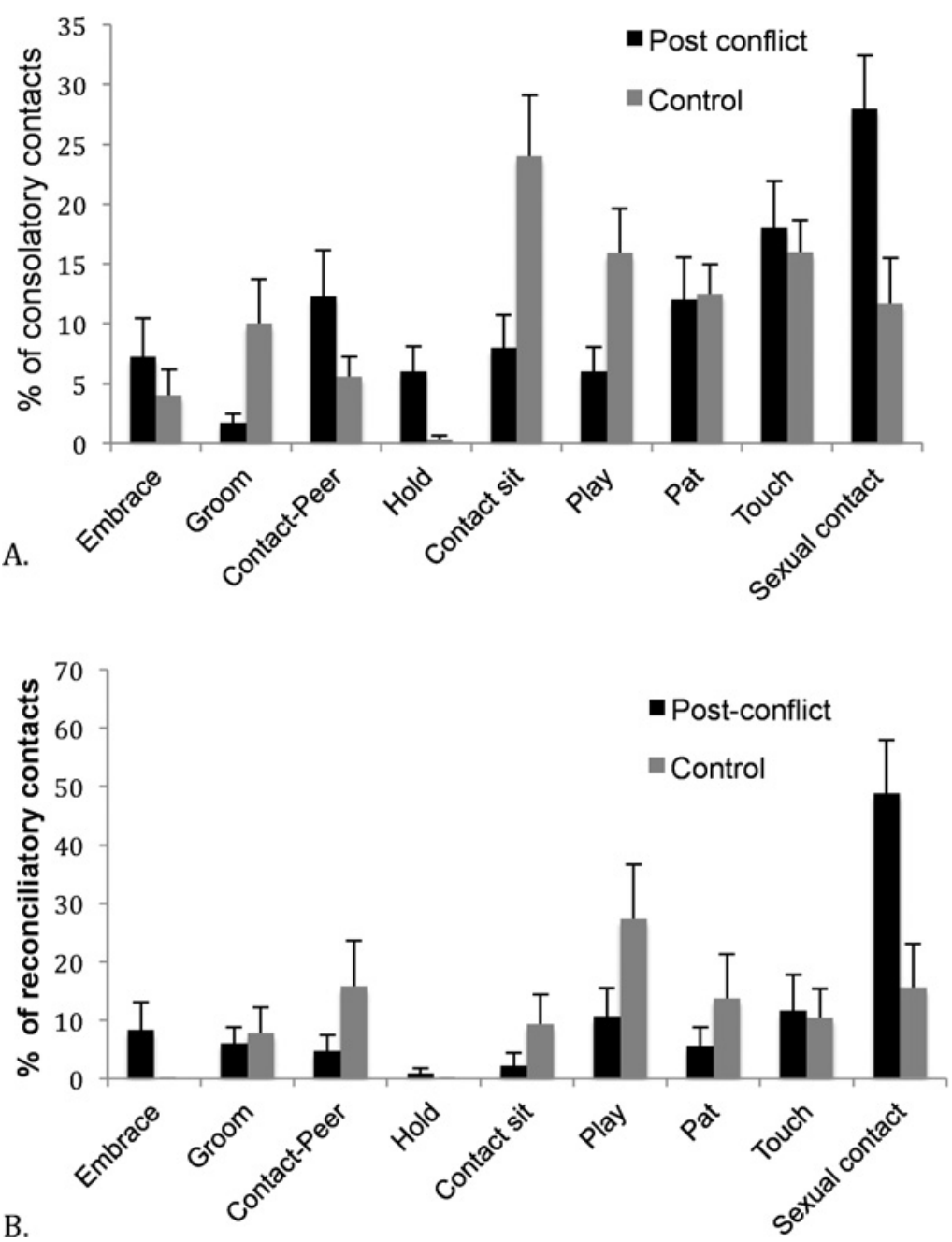

Figure 2. Percentage of post-conflict contact affiliations that contained elements of one of nine behavioral categories during (A) consolation or (B) reconciliation as compared to control periods. The bar chart represents means \pm SEM that were based on mean $\%$ per bystander (consolation) or per victim (reconciliation).

There was significant variation in the rates of different reconciliatory contacts occurring between former opponents as compared to MCs $\left(\chi^{2}=\right.$ 25.558, $\mathrm{df}=8, p=0.0013)$. Again, sexual contacts were significantly more likely between former opponents during PC periods as compared to controls $(\beta=1.876$, S.E. $=0.594, Z=3.008, p=0.002$; Figure 2B). Despite inter- 
individual variation, sexual contact was used significantly more frequently in reconciliation compared to in consolation (mean $\%$ of reconciliatory contacts that were sexual: $50 \pm 43.4 \%$; mean $\%$ consolatory contacts that were sexual $=28 \pm 22 \% ; \chi^{2}=5.466, \mathrm{df}=1, p=0.019$ ), suggesting sexual contacts are important as a form of reconciliatory behaviour in bonobos. While embracing slightly increased during PC periods, and control periods were characterized by increased play and grooming, overall sample sizes for these other behaviours were low and failed to show any significant differences (play: $\beta=-0.672$, S.E. $=0.645, Z=-1.042, p=0.297$; groom: $\beta=-0.098$, S.E. $=0.808, Z=-0.122, p=0.901)$.

\subsection{The use and determinants of post-conflict sexual contacts}

The best fitting GLMM model for consolation only included bystander age $\left(\mathrm{AIC}=332.75, \chi^{2}=3.03, \mathrm{df}=0, p=0.001\right)$. This model fitted significantly better than the null model, which only included random factors $(p<0.001)$. Adults were significantly more likely to offer sexual contacts than juveniles $(\beta=1.157$, S.E. $=0.491, Z=2.353, p \leqslant 0.019)$ or adolescents $(\beta=1.231$, S.E. $=0.628, Z=1.960, p \leqslant 0.050)$. However, there was no effect of the age or sex of the bonobos these adult bystanders targeted, as indicated by the removal of factors of victim age and sex. Similarly, the model for reconciliation revealed that only victim age significantly contributed to the best fitting model (AIC $=89.99, \chi^{2}=-39.993, \mathrm{df}=0$, $p<0.001$ ) with both juvenile and adolescent victims less likely to engage in sexual reconciliation as compared to adults (adolescents: $\beta=-3.002$, S.E. $=1.107, Z=-2.712, p=0.006$; juveniles: $\beta=-2.001$, S.E. $=1.099$, $Z=-1.820, p=0.068)$.

\subsubsection{Does post-conflict sexual contact alleviate victim stress?}

Mean rates of self-scratching were significantly reduced when victims received sexual consolatory contacts (mean rate of self-scratching per victim (per min) after sexual consolatory contacts $=0.13 \pm 0.21$, and after non-sexual consolatory contacts $=0.36 \pm 0.32$; Wilcoxon signed ranks test on mean rates per individual victim: $Z=-2.614, N_{1}=26, N_{2}=23$, $p=0.009$, Figure 3 ). While the offering of sexual reconciliatory contact showed a trend in the same direction (mean rate of self-scratching for sexual reconciliatory contacts $=0.21 \pm 0.22$, non-sexual reconciliatory contacts $=$ $0.31 \pm 0.25$ ), sample sizes for paired analyses were very low and the result was not significant $(Z=-1.355, N=7$ pairs, $p=0.17)$. 


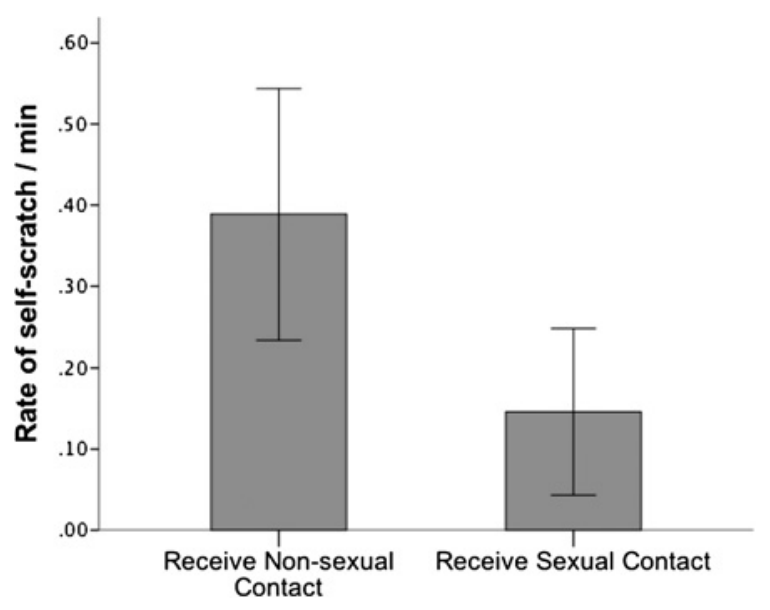

Figure 3. Mean \pm SEM rate of victim self-scratching during post-conflict periods in which the victim received sexual or non-sexual consolatory contact.

\subsubsection{Does post-conflict sexual contact confer reproductive benefits?}

Against this hypothesis, copulations between reproductively viable partners were extremely rare, with the vast majority of PC sexual contacts nonreproductive in nature (i.e., $88 \%$ of $N=91$ consolatory sexual contacts; $94.4 \%$ of $N=36$ reconciliatory sexual contacts were non-reproductive). Offering genito-genital contacts outweighed all other sexual behaviours in both consolation and reconciliation (Figure 4). There were also no cases where adult male bystanders or opponents initiated copulations with female victims. In the case of consolation, copulations were only initiated by adult females and juvenile males ( $N=9$ and $N=4$, respectively), whose targets were mostly non-adults. Only $6 \%$ of consolatory sexual contacts could potentially have led to conception ( $N=6$ copulations were offered by adult females to $N=1$ adult male victim and to $N=5$ adolescent male victims). The reproductively viable sexual contacts (adult females and adolescent males) are shown in Figure 5. No heterosexual copulations were observed at all for reconciliation.

\subsubsection{Does post-conflict sexual contact mediate food-related conflicts?}

GLMM analyses revealed no significant relationship between the occurrence of sexual behaviours and the conflict context for both consolation or reconciliation, suggesting that sexual contacts were not used particularly for mediating food-related conflicts $(\beta=-0.292$, S.E. $=0.356, Z=-0.822$, $p=0.411)$. 

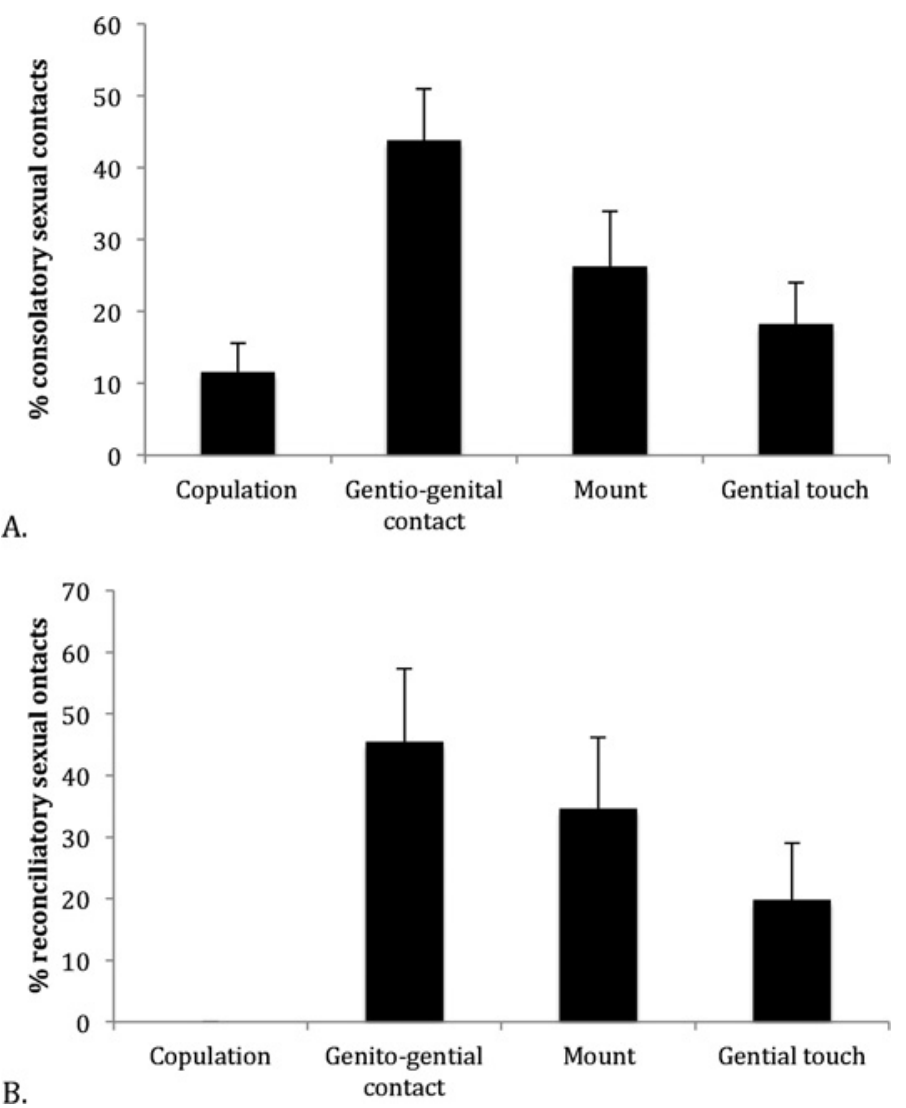

Figure 4. Percentage of (A) consolatory sexual contacts initiated by bystanders to victims and (B) reconciliatory sexual contacts occurring between former opponents. The bar chart represents mean \pm SEM percentages, based on mean $\%$ of total sexual contacts offered per bystander (A) or per victim (B) $(N=23$ for consolation, $N=14$ for reconciliation).

\subsubsection{Does post-conflict sexual contact repair valuable social bonds?}

The affiliative relationship between victims and bystanders (consolation) or former opponents (reconciliation) had no significant effect on the occurrence of PC sexual contact behaviours $(\beta=-0.387$, S.E. $=0.232, Z=-1.667$, $p=0.096)$. In a subsequent analysis in which all kin dyads were removed, the result still remained non-significant. Note that this analysis was specifically for sexual vs. non-sexual contacts, because overall we found affiliative relationships to be a potential factor in predicting PC contact (Clay \& de Waal, 2013a). 


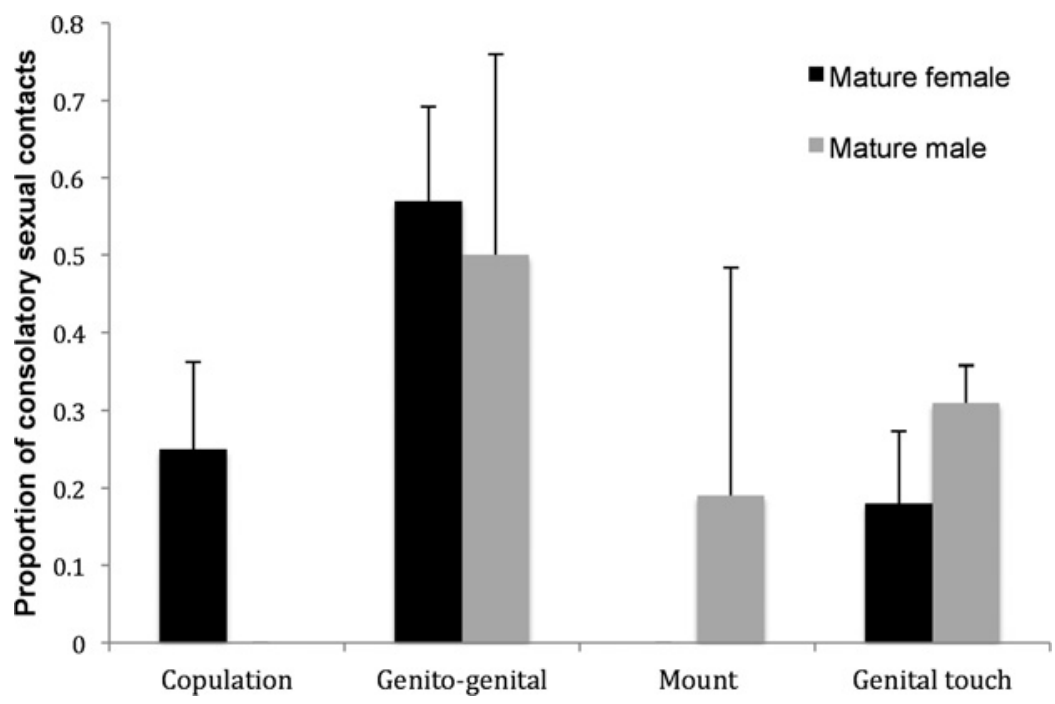

Figure 5. Percentage of sexual contacts initiated by sexually-mature males ( $N=5$ females, $N=7$ males) and female bystander towards victims of aggression. Means \pm SEM were based on mean $\%$ of sexual contacts offered per bystander per sex category (Male, Female).

\section{Discussion}

Following aggressive conflict, bonobos use a suite of sexual and, to a lesser extent, non-sexual behaviours to reconcile with former opponents and, as bystanders, to console distressed victims. Reconciliation and consolation were marked by pronounced increases in sexual behaviours, which included genito-genital contacts, mounting, genital touch and, to a lesser extent, copulation. Reconciliation was almost exclusively characterized by sexual contacts. While sexual contacts were also the most frequently occurring consolatory behaviour, consolation included a rise in other behaviours (embrace, touch, contact peering and holding). Grooming, play, and contact sitting occurred more frequently during baseline, suggesting these behaviours are more relevant for down-tempo social affiliation. Adults were more likely to engage in post-conflict sexual behaviours than adolescents and juveniles, indicating that the sexual nature of conflict resolution strengthens with age in bonobos and that the mechanisms underlying post-conflict behaviours are likely to vary across development.

In accordance with the tension regulation hypothesis, victims receiving sexual contact showed significantly lower rates of self-scratching compared 
to receiving non-sexual consolatory contact. While receiving any form of consolatory contact appears to be calming (as indicated by reduced selfscratching: Clay \& de Waal, 2013a, b), the results further specify that sexual contacts are the most effective in doing so. Further research examining the physiological and behavioural effects of post-conflict sexual contacts is needed to further probe the role of sex in tension regulation in this species, as well as to verify whether other differences between sexual and non-sexual contacts, such as duration of bodily contact, may account for differences in their effects. Moreover, as the artificially close proximity of bonobos within the sanctuary setting may have resulted in increased reconciliation and consolation rates (i.e., individuals sleep together in dormitories at night, thus reducing the possibility of post-conflict avoidance, see Palagi et al., 2006), the next step is to verify whether similar effect exist in the wild.

Consistent with previous studies, genito-genital contacts were the most frequently offered form of sexual contact (de Waal, 1987; Hohmann \& Fruth, 2000; Paoli et al., 2006). Mounting and genital touches were also frequently observed for both consolation and reconciliation. While, bonobos exhibit a particularly heightened level of sexuality compared to other primates, their use of genial touching and mounting during post-conflict periods appears to reflect a broader relationship for primates between sex and social tension (Hanby, 1977). In several species of macaques, for example, female-female mounting and other forms of genital touching occur frequently during postconflict interactions (Macaca nemestrina: Oi, 1991; Flack \& de Waal, 2007; M. arctoides: Call et al., 1999, 2002; M. nigra: Dixson, 1977). Chimpanzees frequently engage in post-conflict mounting and genital touching (i.e., testicle shakes: Arnold et al., 2001; Romero et al., 2011), as well as during other tense periods, such as during predator or inter-group encounters (Goodall et al., 1979; Herbinger et al., 2009).

We did not find support for the hypothesis that post-conflict sexual contacts are part of a reproductive strategy. Consolatory copulations were very rare, with only $6 \%$ of all sexual contacts potentially resulting in conception. Copulation was absent during reconciliation events. This is consistent with a previous study showing an increase in non-conceptive but not conceptive sexual behaviours during periods of short-term crowding and feeding (Palagi et al., 2006).

Although feeding and the anticipation of feeding are associated with socio-sexual behaviours in bonobos (Kuroda, 1984; Thompson-Handler et 
al., 1984; de Waal, 1987; Kano, 1992; Hohmann et al., 2009), we found no evidence that socio-sexual behaviours were used to resolve conflicts arising over food per se. Thus, while anticipation of potential competition or conflict may induce tension (Hohmann et al., 2009) and consequently, trigger sexual responses, sexual behaviours are not necessarily more effective than other contact in mediating the conflict that ensues.

While we have previously shown that affiliation predicts the overall occurrence of consolation and reconciliation in bonobos (Clay \& de Waal, 2013a, b), we did not find support for the hypothesis that post-conflict sexual contacts were specifically directed towards close friends. This consequently does not support the alternative possibility that sexual interactions with socially-distant individuals are perceived as socially risky and thus avoided. The non-significant effect prevailed in a subsequent analysis, where kin dyads were removed, suggesting that this was not simply due to a correlation between affiliation and relatedness. This pattern is somewhat consistent with a study of post-conflict behaviour in stump-tailed macaques (Call et al., 2002), which showed that victims both received and directed socio-sexual behaviours to all non-kin recipients, regardless of affiliation level. The authors suggested that post-conflict socio-sexual behaviours in stump-tailed macaques, also a socially tolerant species, might reduce the risk of further or ongoing aggression, while post-conflict allo-grooming behaviours repaired damaged social relationships. However, our results did not show comparable increases in grooming during post-conflict interactions, suggesting a difference between both species.

While questions remain, our study nevertheless suggests that studying conflict dynamics in socially tolerant species, such as bonobos and stump tailed-macaques, can provide a useful means to explore the complexities and subtleties of triadic conflict interactions and to explore the role of sexual behaviour in regulating social tension.

\section{Acknowledgements}

We are very grateful to Brian Hare and Shinya Yamamoto for inviting us to contribute to the IPS Congress 2013 Symposium and this accompanying Special Issue on 'Bonobos: The newly discovered ape'. We thank Pitshou Nsele Kayanga for assistance in data collection. We are grateful to Claudine André, Fanny Mehl, Dominique Morel, Valery Dhanani and Pierrot 
Mbonzo for their collaboration and to the Ministries of Research and Environment in the DR Congo for supporting our research (research permit: MIN.RS/SG/004/2009). We thank the staff of Lola ya Bonobo for their support, particularly to Stany Mokando, Jean-Claude Nzumbi and Philippe Kunaka. We thank Brian Hare for ongoing support and Tim Eppley for valuable practical assistance. We thank two anonymous Reviewers for their comments. This study was funded by the Living Links Center, part of the Yerkes National Primate Research Center, and Emory University's College for Arts $\&$ Sciences.

\section{References}

Arnold, K. \& Whiten, A. (2001). Post-conflict behaviour of wild chimpanzees (Pan troglodytes schweinfurthii) in the Budongo Forest, Uganda. — Behaviour 138: 649-690.

Blount, B.G. (1990). Issues in bonobo (Pan paniscus) sexual behavior. - Am. Anthropol. 92: 702-714.

Byrne, R., Lee, P.C., Njiraini, N., Poole, J.H. \& Sayialel, K. (2008). Do elephants show empathy? - J. Conscious. Stud. 15: 10-11.

Call, J., Aureli, F. \& de Waal, F.B.M. (1999). Reconciliation patterns among stumptailed macaques: a multivariate approach. - Anim. Behav. 58: 165-172.

Call, J., Aureli, F. \& de Waal, F.B.M. (2002). Postconflict third-party affiliation in stumptailed macaques. - Anim. Behav. 63: 209-216.

Clay, Z. \& de Waal, F.B.M. (2013a). Bonobos respond to distress in others: consolation across the age spectrum. - PLoS One 8: e55206.

Clay, Z. \& de Waal, F.B.M. (2013b). Development of socio-emotional competence in bonobos. - Proc. Natl. Acad. Sci. USA 110: 18121-18126.

Clay, Z., Pika, S., Gruber, T. \& Zuberbühler, K. (2011). Female bonobos use copulation calls as social signals. - Biol. Lett. 5: 513-516.

Cools, A.K.A., van Hout, A.J.M. \& Nelissen, M.H.J. (2008). Canine reconciliation and third party initiated postconflict affiliation: do peacemaking social mechanisms in dogs rival those of higher primates? - Ethology 114: 53-63.

Cordoni, G., Palagi, E. \& Tarli, S.B. (2006). Reconciliation and consolation in captive western gorillas. - Int. J. Primatol. 27: 1365-1382.

Dahl, J.F. (1986). Cyclic perineal swelling during the intermenstrual intervals of captive female pygmy chimpanzees (Pan paniscus). - J. Hum. Evol. 15: 369-385.

de Waal, F.B.M. (1987). Tension regulation and non-reproductive functions of sex in captive bonobos. - Nat. Geo. Res. 3: 318-335.

de Waal, F.B.M. (1989). Peacemaking among primates. - Harvard University Press, Cambridge, MA.

de Waal, F.B.M. (1992). Appeasement, celebration, and food sharing in the two Pan species. — In: Topics in primatology, Vol. 1, Human origins (Nishida, T., McGrew, W.C., Marler, P., Pickford, M. \& de Waal, F.B.M., eds). University of Tokyo Press, Tokyo, p. 37-50. 
de Waal, F.B.M. (1995). Sex as an alternative to aggression in the bonobo. — In: Sexual nature, sexual culture (Abramson, P.R. \& Pinkerton, S.D., eds). University Press of Chicago, Chicago, IL.

de Waal, F.B.M. \& Aureli, F. (1996). Consolation, reconciliation, and a possible cognitive difference between macaques and chimpanzees. - In: Reaching into thought: the minds of the great apes. Cambridge University Press, New York, NY, p. 80-110.

de Waal, F.B.M. \& van Roosmalen, A. (1979). Reconciliation and consolation among chimpanzees. - Behav. Ecol. Sociobiol. 5: 55-66.

de Waal, F.B.M. \& Yoshihara, D. (1983). Reconciliation and redirected affection in rhesusmonkeys. - Behaviour 85: 224-241.

Dixson, A.F. (1977). Observations on the displays, menstrual cycles and sexual behavior of the "Black ape" of Celebes (Macaca nigra). — J. Zool. 182: 63-84.

Flack, J.C. \& de Waal, F.B.M. (2007). Context modulates signal meaning in primate communication. - Proc. Natl. Acad. Sci. USA 104: 1581-1586.

Fraser, O.N. \& Aureli, F. (2008). Reconciliation, consolation and postconflict behavioral specificity in chimpanzees. — Am. J. Primatol. 70: 1114-1123.

Fraser, O.N. \& Bugnyar, T. (2010). Do ravens show consolation? Responses to distressed others. - PloS One 5: 10605.

Fraser, O.N., Stahl, D. \& Aureli, F. (2008). Stress reduction through consolation in chimpanzees. - Proc. Natl. Acad. Sci. USA 105: 8557-8562.

Fraser, O.N., Koski, S.E., Wittig, R.W. \& Aureli, F. (2009). Why are bystanders friendly to recipients of aggression? - Commun. Integr. Biol. 2: 285-291.

Fruth, B. \& Hohmann, G. (2006). Social grease for females? Same-sex genital contacts in wild bonobos. - In: Homosexual behaviour in animals: an evolutionary perspective (Sommer, V. \& Vasey, P., eds). Cambridge University Press, Cambridge, p. 294-315.

Furuichi, T. (1989). Social interactions and the life history of female Pan paniscus in Wamba, Zaire. — Int. J. Primatol. 10: 173-197.

Goodall, J., Bandura, A., Bergmann, E., Busse, C., Matam, H., Mpongo, E., Pierce, A. \& Riss, D. (1979). Inter-community interactions in the chimpanzee populations of the Gombe National Park. — In: The great apes (Hamburg, D. \& McCown, E., eds). Benjamin/Cummings, Menlo Park, CA, p. 13-53.

Hanby, J.P. (1977). Social factors affecting primate reproduction. — In: Handbook of sexology (Money, J. \& Mustaph, H., eds). Excerpta Medica, Amsterdam, p. 461-484.

Hashimoto, C. (1997). Context and development of sexual behaviour of wild bonobos (Pan paniscus) at Wamba, Zaire. - Int. J. Primatol. 18: 1-21.

Herbinger, I., Papwoth, S., Boesch, C. \& Zuberbuhler, K. (2009). Vocal, gestural and locomotor responses of wild chimpanzees to familiar and unfamiliar intruders: a playback study. - Anim. Behav. 78: 1389-1396.

Hohmann, G. \& Fruth, B. (2000). Use and function of genital contacts among female bonobos. - Anim. Behav. 60: 107-120.

Hohmann, G., Mundry, R. \& Deschner, T. (2009). The relationship between socio-sexual behavior and salivary cortisol in bonobos: tests of the tension regulation hypothesis. Am. J. Primatol. 71: 223-232. 
Kano, T. (1989). The sexual behavior of pygmy chimpanzees. - In: Understanding chimpanzees (Heltne, G. \& Marquardt, L.A., eds). Harvard University Press, Cambridge, MA, p. 176-183.

Kano, T. (1992). The last ape: pygmy chimpanzee behavior and ecology. — Stanford University Press, Stanford, CA.

Koski, S.E. \& Sterck, E.H.M. (2007). Triadic postconflict affiliation in captive chimpanzees: does consolation console? - Anim. Behav. 73: 133-142.

Kuroda, S.J. (1980). Social behavior of the pygmy chimpanzees. — Primates 21: 181-197.

Kuroda, S.J. (1984). Interaction over food among pygmy chimpanzees. - In: The pygmy chimpanzee: evolutionary biology and behavior (Susman, R.L., ed.). Plenum Press, New York, NY, p. 301-324.

Maestripieri, D., Schino, G., Aureli, F. \& Troisi, A. (1992). A modest proposal - displacement activities as an indicator of emotions in primates. — Anim. Behav. 44: 967-979.

Manson, J.H., Perry, S. \& Parish, A.R. (1997). Nonconceptive sexual behavior in bonobos and capuchins. — Int. J. Primatol. 18: 767-786.

Mori, A. (1983). Comparison of the communicative vocalizations and behaviors of group ranging in eastern gorillas, chimpanzees and pygmy chimpanzees. — Primates 24: 486500 .

Oi, T. (1991). Non-copulatory mounting of wild pig-tailed macaques (Macaca nemestrina nemestrina) in West Sumatra, Indonesia. — In: Primatology today (Ehara, A., Kimura, T., Takenaka, O. \& Iwamoto, M., eds). Elsevier Science, Amsterdam, p. 147-150.

Palagi, E. \& Cordoni, G. (2009). Postconflict third-party affiliation in Canis lupus: do wolves share similarities with the great apes? - Anim. Behav. 78: 979-986.

Palagi, E., Paoli, T. \& Borgognini Tarli, S. (2004). Reconciliation and consolation in captive bonobos (Pan paniscus). — Am. J. Primatol. 62: 15-30.

Palagi, E., Paoli, T. \& Borgognini Tarli, S. (2006). Short-term benefits of play behavior and conflict prevention in Pan paniscus. — Int. J. Primatol. 27: 1257-1270.

Paoli, T., Palagi, E., Tacconi, G. \& Tarli, S.B. (2006). Perineal swelling, intermenstrual cycle, and female sexual behavior in bonobos (Pan paniscus). - Am. J. Primatol. 68: 333-347.

Parish, A.R. (1994). Sex and food control in the uncommon chimpanzee - how bonobo females overcome a phylogenetic legacy of male-dominance. - Ethol. Sociobiol. 15: 157-179.

Preston, S.D. \& de Waal, F.B.M. (2002). Empathy: its ultimate and proximate bases. Behav. Brain. Sci. 25: 1-71.

Romero, T., Castellanos, M.A. \& de Waal, F.B.M. (2010). Consolation as possible expression of sympathetic concern among chimpanzees. — Proc. Natl. Acad. Sci. USA 107: 1211012115.

Romero, T., Castellanos, M.A. \& de Waal, F.B.M. (2011). Post-conflict affiliation by chimpanzees with aggressors: other-oriented versus selfish political strategy. — PloS One 6: 22173.

Rosati, A.G. \& Hare, B. (2012). Chimpanzees and bonobos exhibit divergent spatial memory. — Dev Sci. 15: 840-853. 
Sapolsky, R.M. (2004). Social status and health in humans and other animals. - Annu. Rev. Anthropol. 33: 393-418.

Schino, G., Perretta, G., Taglioni, A., Monaco, V. \& Troisi, A. (1996). Primate displacement activities as an ethopharmacological model of anxiety. - Anxiety 2: 186-191.

Tabachnick, B.G. \& Fidell, L.S. (2001). Using multivariate analysis. - California State University Northridge, Harper Collins College Publishers, Northridge, CA.

Thompson-Handler, N.T., Malenky, R.K. \& Badrian, N. (1984). Sexual behavior of Pan paniscus. - In: The pygmy chimpanzee: evolutionary biology and behavior (Susman, R.L., ed.). Plenum Press, New York, NY, p. 347-368.

White, F.J. (1996). Comparative socio-ecology of Pan paniscus. — In: Great ape societies (McGrew, W.C., Marchandt, L.F. \& Nishida, T., eds). Cambridge University Press, Cambridge, p. 29-41.

Wobber, V., Wrangham, R. \& Hare, B. (2010). Bonobos exhibit delayed development of social behavior and cognition relative to chimpanzees. - Curr. Biol. 20: 226-230. 